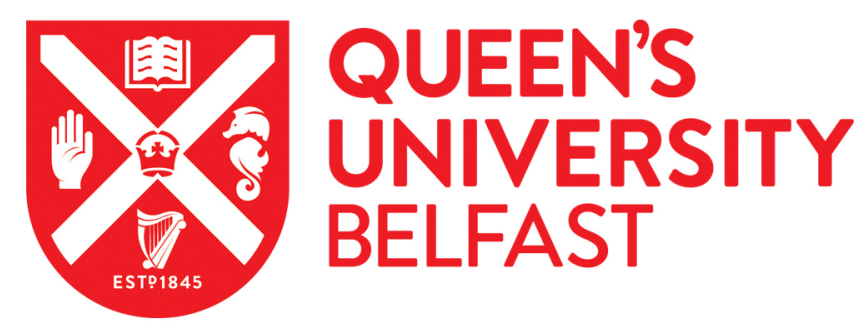

\title{
A 5.6-GHz Class-DE Power Amplifier with Reduced Voltage Stress in 22-nm FDSOI CMOS
}

Love, M., Thian, M., van der Wilt, F., van Hartingsveldt, K., \& Kianush, K. (2020). A 5.6-GHz Class-DE Power Amplifier with Reduced Voltage Stress in 22-nm FDSOI CMOS. In IEEE Asia-Pacific Microwave Conference $(A P M C)$, Singapore Institute of Electrical and Electronics Engineers Inc.. https://doi.org/10.1109/APMC46564.2019.9038363

Published in:

IEEE Asia-Pacific Microwave Conference (APMC), Singapore

Document Version:

Peer reviewed version

Queen's University Belfast - Research Portal:

Link to publication record in Queen's University Belfast Research Portal

Publisher rights

Copyright 2019 IEEE. This work is made available online in accordance with the publisher's policies. Please refer to any applicable terms of use of the publisher.

\section{General rights}

Copyright for the publications made accessible via the Queen's University Belfast Research Portal is retained by the author(s) and / or other copyright owners and it is a condition of accessing these publications that users recognise and abide by the legal requirements associated with these rights.

Take down policy

The Research Portal is Queen's institutional repository that provides access to Queen's research output. Every effort has been made to ensure that content in the Research Portal does not infringe any person's rights, or applicable UK laws. If you discover content in the Research Portal that you believe breaches copyright or violates any law, please contact openaccess@qub.ac.uk. 


\section{A 5.6-GHz Class-DE Power Amplifier with Reduced Voltage Stress in 22-nm FDSOI CMOS}

\author{
Matthew Love \\ Queen's University of Belfast \\ Northern Ireland \\ mlove05@qub.ac.uk
}

\author{
Mury Thian \\ Queen's University of Belfast \\ Northern Ireland \\ m.thian@qub.ac.uk
}

\author{
Floris van der Wilt \\ Catena Microelectronics B.V. \\ The Netherlands
}

\author{
Koen van Hartingsveldt \\ Catena Microelectronics B.V. \\ The Netherlands
}

\author{
Kave Kianush \\ Catena Microelectronics B.V. \\ The Netherlands
}

\begin{abstract}
This paper presents a $5.6 \mathrm{GHz}$ Class-DE power amplifier (PA) with reduced voltage stress compared to classical PA designs. CMOS PAs are susceptible to a number of breakdown phenomena such as drain oxide breakdown and hot-carrier injection (HCI) which can significantly reduce their lifespan. The Class-DE amplifier is a hard-switching device which minimizes voltage-current overlap across the channel which significantly reduces the risk of $\mathrm{HCI}$ effects. The PA does not use an RF choke which limits the peak drain voltage to $V_{D D}$, limiting the risk of drain oxide breakdown. The driver circuit gives a duty cycle below $50 \%$ and ensures that each transistor is almost completely off before the other has turned on. The PA achieves 47.9\% power-added efficiency, $22.2 \mathrm{dBm}$ output power, and 28.2 $\mathrm{dB}$ gain with a single $2.2 \mathrm{~V}$ supply voltage. Transient simulations of the PA's drain currents and voltages confirm the low currentvoltage overlap which shows that the PA has much less risk of HCI effects than classical PA designs.
\end{abstract}

Index Terms-22 nm, $5 \mathrm{GHz}$, CMOS, hot-carrier injection, integrated circuit, oxide breakdown, power amplifier

\section{INTRODUCTION}

There is high interest in the design of silicon radiofrequency integrated circuits (RFIC) as it is the only semiconductor technology that can integrate high-density digital, analog, and RF components on a single chip. The high levels of circuit integration enables the creation of extremely compact circuits with high yields which are of high importance for the upcoming Internet of Things. The power amplifier (PA) is one of the most difficult circuits to design as it is responsible for the majority of the DC power consumption. A major challenge in CMOS PA design is the device reliability due to the low drain breakdown voltage and hot-carrier injection (HCI). Drain breakdown is caused by an excessively high voltage potential across the transistor channel and thus stacked PAs are increasingly being used to spread this stress over multiple transistors to overcome the limitations of the low supply voltages though this can complicate the circuit design [1]. Even with the stacked PA technique, the peak drain voltage for classical PAs is at least $2 V_{D D}$ due to the RF choke inductor and is as high as $3.56 V_{D D}$ in Class-E which presents a significant reliability concern. Hot-carrier injection is the

This work was supported by the UK Engineering and Physical Sciences Research Council (EPSRC) under grant no. EP/P013031/1. process of charge carriers being accelerated to a high speed and leaving the channel and becoming trapped in surrounding insulators. HCI results in a number of changes including a threshold voltage shift and a reduction in drain current. These issues can severely degrade the output power, efficiency, and linearity of a PA. HCI occurs when the channel voltage and current overlap is significant, as in a Class- $\mathrm{AB}$ amplifier, and thus is much less of an issue for switching amplifiers as they ideally have zero overlap of drain current and voltage. This paper presents a low-stress power-combined $5.6 \mathrm{GHz}$ ClassDE PA on the GlobalFoundies 22FDX CMOS process.

\section{Circuit Design And Description}

The Class-DE amplifier combines the complementary common-source (CS) Class-D structure with load network from Class-E to enable zero voltage switching (ZVS) and zero voltage-derivative switching (ZVDS) from Class-E with the addition of a dead-time between the switching transitions [2]. The absense of an RF choke inductor with the the complementary CS structure results in no drain voltage multiplication which significantly reduces the risk of device breakdown compared to other classes. The device is a hardswitching PA which has very low HCI risk due to the ideally zero drain current-voltage overlap. The Class-DE PA has a dead-time which minimizes the shoot-through effect where a low-impedance path is formed between the supply voltage and ground during switching and this significantly increases the PA efficiency.

The PA uses a two-way unisolated power-combined design with a unit cell shown in Fig. 1. The $L C C$ matching network in Fig. 1 is matched to $100 \Omega$ to include the combiner losses in the unit cell design. Load-pull was used to find the optimum impedance with $L_{1} C_{2} C_{3}$ transforming the $100 \Omega$ load to $Z_{\text {opt }}=6.6+j 0.9$. The two cells are combined in parallel and connected to a $50 \Omega$ load in the final circuit. To improve the output power, the supply voltage is $2.2 \mathrm{~V}$, giving a $\left|V_{D S}\right|$ of $1.1 \mathrm{~V}$ per device in the stack which is only $16 \%$ higher than the maximum digital overdrive voltage of $0.95 \mathrm{~V}$ and thus should not cause reliability issues.

The driver consists of seven Class-D stages with each stage having twice the width of the previous one. This was done 


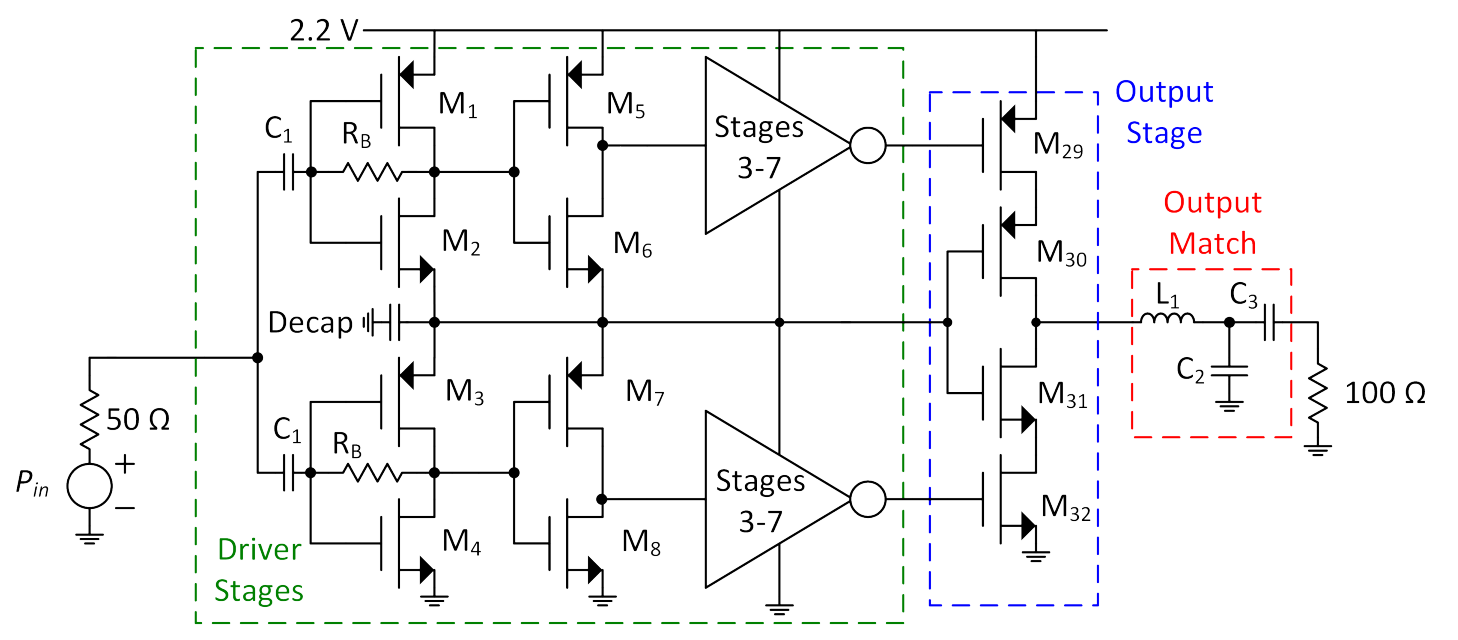

Fig. 1. Class-DE PA unit cell. Stages 3-7 are identical in structure to stage 2 except with increasingly wider channels.

to quickly charge the output stage gate capacitances while ensuring short transition times between each driver stage to minimize the driver's dynamic power consumption. The risk of instability due to the high open-loop gain is mitigated by self-biasing only the first stage with resistor $R_{B}$, rather than self-biasing every stage, as the PA remains off unless the input power exceeds a certain threshold which eliminates the risk of small oscillations activating the PA. For PAs operated at a single input power, this presents no issues.

Separate driver chains are used for $M_{29}$ and $M_{32}$ to enable the entire circuit to operate from a single $2.2 \mathrm{~V}$ supply and to generate a dead time during circuit transitions. The voltage drop across the top chain provides the required $1.1 \mathrm{~V}$ for the lower chain eliminating the need for a second supply voltage which simplifies the circuit layout as the thick metal layers do not have to be partitioned for each supply voltage. This is a similar concept to the original stacked power amplifier technique which stacked common-source transistors to use a higher DC supply voltage [3]. Decoupling capacitors are needed to provide an RF ground for the source of the PMOSs in the lower driver chain. The dead time is implemented by increasing the width of $M_{1}$ and $M_{4}$ which speeds up the charging and discharging of $M_{6}$ and $M_{7}$ 's gate capacitances respectively which keeps them turned off for longer [4]. The output waveforms of the final driver stage are shown in Fig. 2 where the dead-time can be seen with $M_{32}$ almost completely off before $M_{29}$ turns on, and vice-versa.

\section{RESULTS}

The circuit performance is plotted in Figs. 3-5 and is summarized in Table I. The circuit has excellent levels of $P A E, P_{\text {out }}$, and gain without over-stressing the devices. The harmonic suppression, shown in Fig. 5, is excellent with the largest harmonic, $2 f_{0}$, at $-40.8 \mathrm{dBc}$. The effect of self-biasing only the first driver stage is seen in Fig. 3 where the PA is off until at least $-24 \mathrm{dBm}$ is applied to the input. The PA reported in [5] was designed in $180 \mathrm{~nm}$ bulk CMOS with a nominal

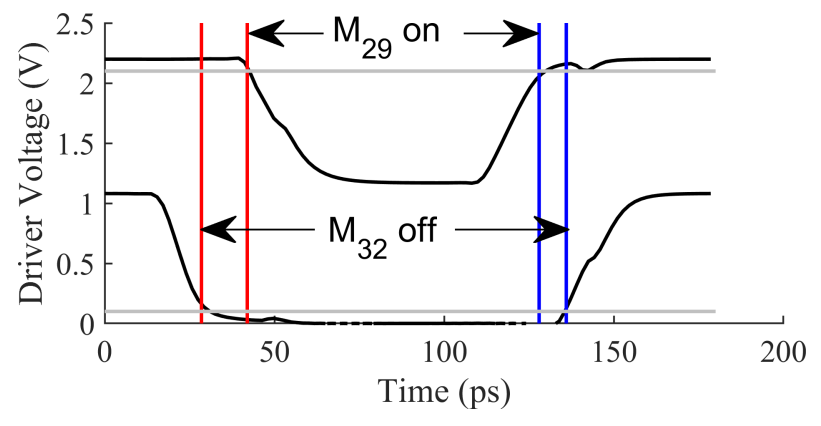

Fig. 2. Driving waveforms for $M_{29}$ (top) and $M_{32}$ (bottom) to cause a deadtime during switching. The two dead-times are bounded with red and blue dashed lines. The gray horizontal lines represent the threshold voltage of the PMOS (top) and NMOS (bottom).

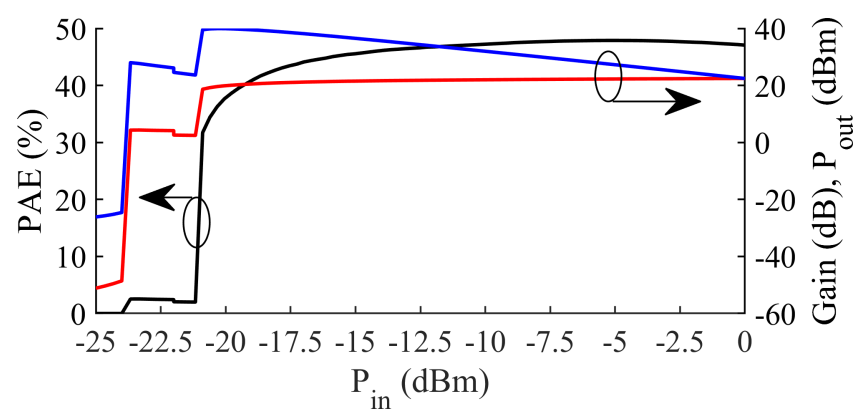

Fig. 3. PAE (black), $P_{\text {out }}$ (red), and gain (blue) versus input power

supply voltage of $1.8 \mathrm{~V}$, and has a peak voltage of $5.8 \mathrm{~V}$ spread over two stacked NMOSs, giving an overvoltage of $60 \%$ compared to $16 \%$ in this work. The waveforms also show a significant current-voltage overlap during oscillation which raises a high risk of breakdown and HCI-related degradation over time. Similarly, the cascode PAs in [6] and [7] have $\left|V_{D S}\right|$ swings that are close or equal to twice the process supply voltage. The three designs in Table I use two to three voltage supplies while this design requires only one. The 
TABLE I

Summary of THE PA Performance VS THE STATE-OF-THE-ART CMOS PAS

\begin{tabular}{ccccccccccc}
\hline \multirow{2}{*}{ Ref } & $\begin{array}{c}\text { CMOS } \\
\text { Process }\end{array}$ & $\begin{array}{c}\text { Frequency } \\
(\mathrm{GHz})\end{array}$ & $\begin{array}{c}P A E \\
(\%)\end{array}$ & $\begin{array}{c}P_{\text {out }} \\
(\mathrm{dBm})\end{array}$ & $\begin{array}{c}\text { Gain } \\
(\mathrm{dB})\end{array}$ & $\begin{array}{c}\text { Bandwidth } \\
(\%)\end{array}$ & $\begin{array}{c}\text { Supply } \\
(\mathrm{V})\end{array}$ & $\begin{array}{c}\text { \# of } \\
\text { Supplies }\end{array}$ & $\begin{array}{c}\text { Overvoltage } \\
(\%)\end{array}$ & $\begin{array}{c}\text { PA } \\
\text { Class }\end{array}$ \\
\hline This work $^{*}$ & $22 \mathrm{~nm}$ FDSOI & 5.6 & 47.9 & 22.2 & 28.2 & 38.4 & 2.2 & 1 & 16 & $\mathrm{DE}$ \\
{$[5]$} & $180 \mathrm{~nm}$ Bulk & 5 & 35.4 & 20 & 20.4 & N/A & 2.3 & 3 & 60 & $\mathrm{E}$ \\
{$[6]$} & $180 \mathrm{~nm}$ Bulk & 4.8 & 41 & 26.2 & 14.3 & N/A & 4 & 3 & 95 & $F^{-1}$ \\
{$[7]^{*}$} & $65 \mathrm{~nm}$ Bulk & 5 & 40 & 22.1 & 9.3 & N/A & 1.36 & 2 & 100 & E \\
\hline
\end{tabular}

* Simulated with foundry models

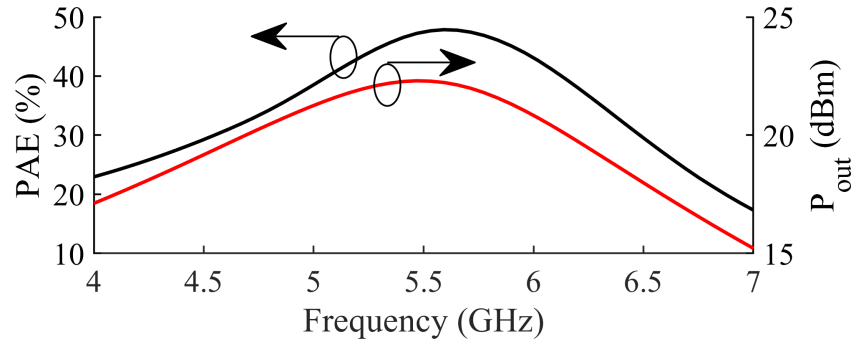

Fig. 4. PAE (black) and Pout (red) versus frequency

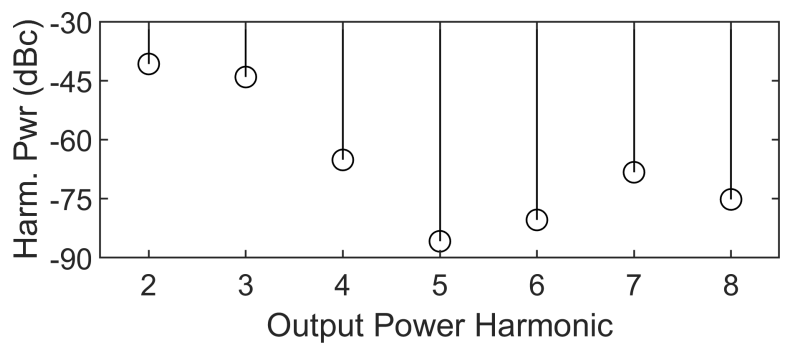

Fig. 5. Harmonic power relative to the fundamental output power

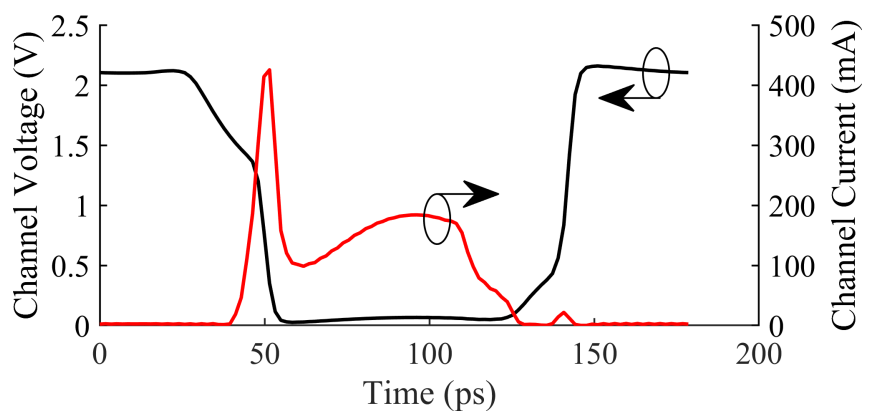

Fig. 6. Voltage (black) and current (red) across $M_{29}$ and $M_{30}$ showing the hard-switching and low current-voltage overlap

frequency sweep in Fig. 4 shows that the peak $P A E$ is $47.9 \%$ at $5.6 \mathrm{GHz}$ and peak $P_{\text {out }}$ of $22.3 \mathrm{dBm}$ at $5.47 \mathrm{GHz}$ with a fractional $-3 \mathrm{~dB}$ output power bandwidth of $38.4 \%$. The channel voltages and currents of the PMOSs and NMOSs in the output stage are plotted in Fig. 6 and Fig. 7 respectively. It can be seen that the circuit is hard-switching with almost no shoot-through current and that the duration of the currentvoltage overlap is extremely short meaning that the risk of damage from HCI is minimal.

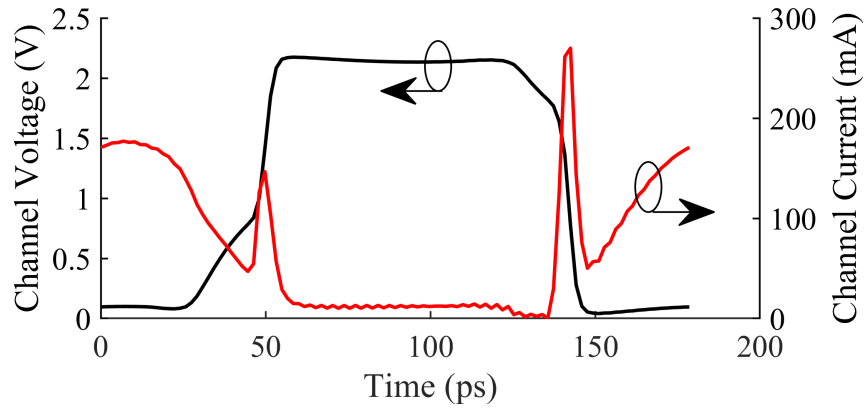

Fig. 7. Voltage (black) and current (red) across $M_{31}$ and $M_{32}$ showing the hard-switching and low current-voltage overlap

\section{CONCLUSION}

A low-stress $5.6 \mathrm{GHz}$ Class-DE PA on 22nm CMOS has been presented with $47.9 \%$ PAE, $22.2 \mathrm{dBm}$ output power, $28.2 \mathrm{~dB}$ gain on a $22 \mathrm{~nm}$ CMOS process using a single $2.2 \mathrm{~V}$ supply voltage. The use of the hard-switching Class$\mathrm{DE}$ amplifier reduces the risk of hot-carrier injection which is a substantial issue in classical PA design. The complementary common-source architecture without the use of an RF choke inductor means the drain voltage never goes above the supply voltage which reduces the chance of drain breakdown.

\section{REFERENCES}

[1] A. K. Ezzeddine and H. C. Huang, "The high voltage/high power FET (HiVP)," in IEEE RFIC, Jun. 2003, pp. 215-218.

[2] A. Alipov and V. Kozyrev, "Push/pull class-DE switching power amplifier," in IEEE IMS, vol. 3, Jun. 2002, pp. 1635-1638 vol.3.

[3] A. Ezzeddine, H. L. A. Hung, and H. C. Huang, "High-Voltage FET Amplifiers for Satellite and Phased-Array Applications," in IEEE IMS, Jun. 1985 , pp. 336-339.

[4] W. Kim, J. Rode, A. Scuderi, H. Son, C. S. Park, and P. M. Asbeck, "An efficient voltage-mode class-D power amplifier for digital transmitters with delta-sigma modulation," in IEEE IMS, Jun. 2011, pp. 1-4.

[5] Y. Yamashita, D. Kanemoto, H. Kanaya, R. K. Pokharel, and K. Yoshida, "A 5-GHz fully integrated CMOS class-E power amplifier using selfbiasing technique with cascaded class-D drivers," in IEEE RFIT, Nov. 2012, pp. 237-239.

[6] J. Nai, Y. Hsiao, Y. Wang, F. Chen, and H. Wang, "5-GHz transformer combined class-F1power amplifier," in IEEE RFIT, Aug. 2016, pp. 1-3.

[7] A. Chakrabarti and H. Krishnaswamy, "An improved analysis and design methodology for RF Class-E power amplifiers with finite DC-feed inductance and switch On-resistance," in IEEE ISCAS, May 2012, pp. 1763-1766. 